\title{
PERCEPÇÕES DE ESTUDANTES DE ENFERMAGEM SOBRE EDUCAÇÃO A DISTÂNCIA
}

\author{
NURSING STUDENTS’ PERCEPTION ON DISTANCE LEARNING
}

\section{PERCEPCIONES DE ESTUDIANTES DE ENFERMERÍA SOBRE EDUCACIÓN A DISTANCIA}

\author{
Lídia Trindade de Castro Silva* \\ Fabricia Almeida Diniz ${ }^{* *}$ \\ Tarcísio LaerTe Gontijo ${ }^{* * *}$ \\ RichaRdSON Miranda MACHADO ${ }^{* * * *}$ \\ Ricardo Bezerra CaVAlCANTE****
}

RESUMO

Objetivo: Analisar a percepção de estudantes de Enfermagem de uma instituição de ensino superior sobre o uso da Educação a Distância (EaD). Método: Trata-se de estudo que utilizou a abordagem qualitativa e entrevistou 12 discentes do curso de graduação em Enfermagem de uma instituição pública de ensino superior. Os dados coletados foram organizados e analisados por meio da Análise de Conteúdo. Resultados: Verificou-se que discentes de enfermagem já possuem experiências variadas em relação à educação a distância permitindo a busca pelo conhecimento, o desenvolvimento profissional e a atualização. Apontaram facilidades em relação à EaD tais como a flexibilidade de horários, a redução de custos, de deslocamentos e o estímulo a autoaprendizagem. Porém destacaram dificuldades relacionadas às questões técnicas, sobrecarga de atividades e dificuldades para o exercício de sua autonomia. A ausência de um processo de capacitação sistemático para a manipulação das tecnologias na EaD também foi outro aspecto levantado pelos entrevistados. Conclusão: A enfermagem tem encontrado na EaD possibilidades de avanços no conhecimento, no aprimoramento, na busca por informação e no desenvolvimento da profissão. Entretanto, desafios precisam ser suplantados, como a necessidade de aprimoramento da própria tecnologia, um processo de capacitação sistemático e contínuo, bem como o desenvolvimento da autonomia nos processos de ensino- aprendizado.

Palavras chave: Educação a distância, educação em enfermagem, tecnologia da informação.

\footnotetext{
ABSTRACT

Objective: This study aimed to analyze the perceptions of Nursing students from a higher education institution on the use of Distance Education. Method: This is a study which used a qualitative approach and interviewed

* Discente do curso de Enfermagem da Universidade São João Del Rei, campus CCO, Divinópolis, MG//Brasil. E-mail: lidiacastro29@gmail.com

** Enfermeira do Trabalho, Mestre em Enfermagem pelo Programa de Pós-graduação Enfermagem da Universidade São João Del Rei, campus CCO, Divinópolis, MG/Brasil. E-mail: fabriciadiniz@bol.com.br

${ }^{* * *}$ Doutorado em Ciências da Saúde, Professor Adjunto III da Universidade Federal de São João Del Rei, campus CCO, Divinópolis, MG/Brasil. E-mail: enftarcisio@ufsj.edu.br

${ }^{* * * *}$ Doutorado em Psiquiatria, Professor Adjunto IV da Universidade Federal de São João Del Rei, campus CCO, Divinópolis, MG/Brasil. E-mail: richardson@usp.br

${ }^{* * * * *}$ Doutorado e Pós Doutorado em Ciência da Informação, Professor Adjunto III da Universidade Federal de São João Del Rei, campus CCO, Divinópolis, MG/Brasil. E-mail: ricardocavalcante@ufsj.edu.br
} 
12 students from an undergraduate Nursing major at a public institution of higher education. The collected data were organized and analyzed using content analysis. Results: It was found that nursing students already have varied experiences regarding Distance Learning, which allows for the search for knowledge, professional development and updating. They identified benefits of distance education such as scheduling flexibility, cost reduction, travelling freedom and the desire for self-learning. However, they highlighted difficulties related to technical issues, task overload and problems to manage autonomy. The absence of a systematic training process to handle technologies used in distance education was another point raised by the respondents. Conclusion: It was concluded that nursing has found in distance education the possibilities for advances in knowledge, improvement in the search for information, and the development of the profession. However, challenges still must be overcome, such as the need to improve the technology itself, having a process of systematic and continuous training, and the development of autonomy in teaching and learning processes.

Key words: Distance education, nursing education, information technology.

\section{RESUMEN}

Objetivo: Analizar la percepción de los estudiantes de Enfermería de una institución de educación superior en el uso de la educación a distancia. Método: Se trata de un estudio con un enfoque cualitativo. Se entrevistó a 12 estudiantes de licenciatura de Enfermería de una institución pública de educación superior. Los datos recogidos fueron organizados y analizados mediante el análisis de contenido. Resultados: Se encontró que los estudiantes de enfermería ya tienen experiencias variadas en relación con la educación a distancia, que permite la búsqueda del conocimiento, el desarrollo profesional y la actualización. Identificaron facilidades en relación a la educación a distancia, tales como la flexibilidad horaria, reducción de costos, desplazamiento y el estímulo de autoaprendizaje. Sin embargo, destacaron dificultades relacionadas con cuestiones técnicas, sobrecarga de actividades y dificultades en el ejercicio de su autonomía. La ausencia de un proceso de capacitación sistemática para el manejo de las tecnologías en la educación a distancia fue otro punto planteado por los encuestados. Conclusión: Enfermería ha encontrado en la educación a distancia posibilidades de avances en el conocimiento, mejora en la búsqueda de información y desarrollo de la profesión. Sin embargo, deben ser superarados desafíos, como la necesidad de mejorar la tecnología en sí misma, un proceso de formación sistemática y continua, así como el desarrollo de la autonomía en los procesos de enseñanza y aprendizaje.

Palabras clave: Educación a distancia, educación en enfermería, tecnologías de la información.

Fecha recepción: 26/11/14 Fecha aceptación: 16/01/16

\section{INTRODUÇÃO}

Por meio do Decreto no 5.662 (1), definiuse a Educação a Distância (EaD) como uma modalidade em que a mediação nos processos de ensino e aprendizagem se dá por meio de tecnologias da informação e comunicação, em lugares e/ou tempos diversificados. A $\mathrm{EaD}$ é uma modalidade onde promove-se a comunicação educativa, através de meios capazes de suprir a distância que separa fisicamente educando e educador (2).
Assim, o aluno pode interagir com tutores/professores, pelo trabalho de administração de fluxos de comunicação exercido por uma organização responsável pelo curso e suporte facilitador dessa interação (3). A EaD não é considerada uma modalidade recente. Os primeiros registros de sua utilização são do início do processo de industrialização quando a necessidade de qualificação e especialização impulsionaram a criação de cursos por correspondência (4).

A EaD historicamente pode ser dividida em gerações: a primeira é denominada de 
modelos de primeira geração, a qual consiste no ensino por meio de correspondências e os manuais, que exerciam a função comunicativa. A segunda é denominada modelos de segunda geração e consiste na transmissão da informação, utilizando-se de meios de comunicação em massa, como rádio e a televisão, além destes, o telefone era utilizado para o envio de perguntas. A terceira é denominada de modelos de terceira geração, a qual consiste no predomínio do uso da teleinformática e dos ambientes virtuais de aprendizagem, como correio eletrônico, a internet, a videoconferência, entre outros (5).

Atualmente a EaD vem se modificando em relação aos seus padrões iniciais. Ampliouse o alcance de sua superfície topológica, $o$ seu perfil se tornou mais dinâmico e novos recursos tecnológicos foram incorporados. $\mathrm{O}$ que se percebe éque $\mathrm{a} \mathrm{ED}$ tem proporcionado novas formas de ensinar, aprender, pesquisar, de maneira específica, contínua e autônoma $(6,7)$.

Essa modalidade de ensino apresenta constante crescimento em diversas áreas, inclusive na área da saúde (8). Neste campo e especificamente na enfermagem, o uso da EaD tornou-se uma realidade principalmente a partir da necessidade de formação de recursos humanos requerida com a implantação do Sistema Único de Saúde (SUS) e estimulada pela descentralização de ações e serviços.

Observa-se que a EaD vem sendo desenvolvida com o objetivo de promover o aprimoramento de profissionais e ganhando destaque na ampliação do acesso à informação e ao conhecimento científico. Isto ocorre devido ao estímulo à autonomia, valorização do aluno e flexibilização do processo de ensino-aprendizagem. Além de reduzir a necessidade de deslocamento e custos $(9,10)$.

A enfermagem, enquanto profissão da área de saúde, também necessita acompanhar este processo de modernização com vistas ao crescimento profissional e a produção de novos conhecimentos. Algumas experiências na en- fermagem utilizando a $\mathrm{EaD}$ vem ocorrendo na pós-graduação, em cursos semipresenciais, em disciplinas na graduação em enfermagem, cursos de extensão, e por meio da educação continuada $(3,6,7,9-11)$. Considerando a existência de várias experiências do uso da $\mathrm{EaD}$ na enfermagem é preciso avançar na compreensão desta modalidade enquanto possibilidade de desenvolvimento do conhecimento nessa área.

Ressalta-se que a educação em enfermagem, seja qual for o nível, pode ser favorecida pelo uso das novas tecnologias da informação e comunicação. Entretanto, a incorporação tecnológica no processo educacional em enfermagem precisa enfatizar a promoção do conhecimento científico, conferindo à profissão, a possibilidade de avanços em sua autonomia, conhecimento e cientificidade. É importante entender as questões que emergem das influências que estas tecnologias podem trazer à profissão, profissionais e acadêmicos. Entretanto é preciso apreender a percepção que se tem destas experiências com a $\mathrm{EaD}$ principalmente a partir da perspectiva de discentes de Enfermagem.

Neste contexto propõem-se o seguinte questionamento: "Como discentes de graduação em enfermagem percebem suas experiências com a Educação a Distância?" Espera-se que este estudo contribua para refletir sobre o uso da $\mathrm{EaD}$ nos processos de ensino e aprendizagem em enfermagem trazendo possibilidades de aprimoramentos deste processo. Enfim, o presente estudo tem por objetivo analisar a percepção de discentes de graduação em enfermagem sobre suas experiências com a EaD.

\section{MÉTODO}

Trata-se de estudo de caso de abordagem qualitativa desenvolvido em uma Instituição Federal de Ensino Superior (IFES) de Minas Gerais, Brasil. A instituição tem investido no 
desenvolvimento da EaD buscando que docentes e discentes estejam envolvidos neste processo. Na instituição há o curso de Enfermagem (modalidade presencial) que obteve nota máxima na avaliação do Ministério da Educação e atualmente conta com 360 alunos e 45 professores, sendo 39 enfermeiros. Os participantes incluídos neste estudo foram discentes de graduação em Enfermagem dos $6^{\circ}$ e $7^{\circ}$ períodos e que já haviam passado por experiências com EaD. A escolha de alunos destes dois períodos específicos se deu pelo fato deles estarem há mais tempo na instituição, gerando maior possibilidade de contato com a EaD. Os alunos do $8^{\circ}$ e $9^{\circ}$ período foram excluídos da amostra devido ao fato de estarem em período de Internato fora da cidade, o que dificultaria muito a coleta de dados.

A entrevista semi-estruturada foi utilizada para a coleta dos dados. Sua utilização se justificou, por ser dotada de ampla comunicação verbal e, no sentido restrito de coleta de informações sobre determinado tema científico é a estratégia mais usada no trabalho de campo (12). As entrevistas foram áudio-gravadas e posteriormente transcritas. Para a realização das entrevistas, utilizou-se roteiro semi-estruturado contendo algumas questões norteadoras: Comente como foi ou como tem sido a sua experiência com $\mathrm{EaD}$; em sua opinião o que facilitou o desenvolvimento desta experiência?; quais foram as dificuldades vivenciadas?; nesta experiência com a EaD houve contribuição para o seu processo de aprendizagem?; você passou por algum processo de capacitação?

Os alunos que se enquadravam nos critérios definidos anteriormente foram convidados a participar do estudo a partir de uma reunião onde se apresentou a pesquisa. Aqueles que concordaram em participar realizaram o agendamento da entrevista com o pesquisador. A coleta de dados ocorreu em sala reservada da referida universidade, previamente agendada no período de setembro de 2013 à fevereiro de 2014.
Para a composição do número de sujeitos entrevistados utilizou-se o critério de saturação. Ressalta-se que nas investigações qualitativas em saúde verifica-se, com frequência, a utilização da saturação de informações como critério para o fechamento amostral ou, ainda, a saturação do universo quando as entrevistas são realizadas com todos os representantes de determinado grupo ou categoria (13). A saturação de informações é definida como a suspensão de inclusão de novos participantes quando os dados obtidos passam a apresentar, na avaliação do pesquisador, certa redundância ou repetição, não sendo considerado relevante persistir na coleta de dados (14).

Para constatação da saturação teórica utilizaram-se os seguintes passos: a) disponibilizar os registros de dados "brutos"; b) "emergir" em cada registro; c) compilar as análises individuais (de cada pesquisador, para cada entrevista); d) reunir os temas ou tipo de enunciado para cada pré-categoria ou nova categoria; e) codificar ou nomear os dados; f) alocar numa tabela os termos e tipos de enunciados (13). Utilizando-se, assim, o critério de saturação chegou-se a um universo de 12 discentes de enfermagem entrevistados. Para manutenção e garantia do anonimato dos entrevistados as falas foram identificadas nesse estudo pela letra "E" seguida do número da entrevista, por exemplo: $\mathrm{E} 1, \mathrm{E} 2, \mathrm{E} 3 \ldots$

Os dados coletados foram analisados por meio da Análise de Conteúdo, modalidade Temático-Categorial (15). A escolha deste método de análise pode ser explicada pela necessidade de ultrapassar as incertezas consequentes das hipóteses e pressupostos, pela necessidade de enriquecimento da leitura por meio da compreensão das significações e pela necessidade de desvelar as relações que se estabelecem além das falas propriamente ditas.

Este estudo obedece aos princípios éticos da Resolução 466/2012 do Conselho Nacional de Saúde e foi aprovado por Comitê de 
Ética em Pesquisa sob o parecer no 011/2011.

\section{RESULTADOS}

Após análise dos dados identificaram-se 4 categorias analíticas a saber: Experiências com $\mathrm{EaD}$ vivenciadas pelos discentes de Enfermagem; Facilidades proporcionadas pela $\mathrm{EaD}$; Dificuldades vivenciadas pelos discentes de Enfermagem e Processo de capacitação para utilização das ferramentas na EaD.

\section{Experiências com EaD vivenciadas pelos discentes de Enfermagem}

Alguns entrevistados apontaram suas experiências com $\mathrm{EaD}$ por meio de participação em disciplinas no curso de graduação em Enfermagem. Ressaltaram a possibilidade de cursarem disciplinas dentro da própria universidade, em campus diferente ou até mesmo em outra universidade.

“(...) Então, eu tive duas experiências. Uma que foi a optativa aqui da faculdade e a outra que é a optativa que eu tô fazendo em outro campus que é sobre educação, que tá trazendo as novas leis de ortografia (...)" (E 1).

“(...) a experiência que a gente teve foi no $5^{\circ}$ período, que a gente já acessava assim a questão do portal (...)” (E 5).

“(...) Eu fiz um curso de uma outra universidade, a experiência foi ótima, o curso durou três meses, 120 horas (...)" (E 12).

Os entrevistados apontaram que suas experiências com $\mathrm{EaD}$ estavam relacionadas com cursos na área da saúde/enfermagem, mas também destacaram cursos em outras áreas, como cursos de inglês.

“(...) Agora o inglês também na plataforma do My English também, que eu acho interessante também (...)" (E 5).

“(...) O recentemente que eu faço na educação a distância é o curso de inglês (...)” (E 6). Um dos entrevistados ainda reconhece que sua experiência com EaD também pode se dar por meio de e-mails ou de redes sociais.

"(...) É só mesmo a troca de e-mails com os professores e por redes sociais, essas coisas” (E 8).

\section{Facilidades proporcionadas pela EaD}

Alguns dos entrevistados apontaram a interatividade professor/aluno como um aspecto facilitador vivenciado na modalidade a distância bem como a diminuição das tensões nesta relação.

“(...) lá tem umas janelinhas de bate-papo que qualquer coisa que você precisar, você já entra em contato direto com o seu professor, pergunta, tira a dúvida e na mesma hora ele te responde (...)" (E 1).

“(...) E essa barreira, essa não presença do professor acaba criando pra gente um facilitador. Pra conversar que às vezes cara a cara tem aquela vergonha ou fica sem jeito e tal. Pela internet, fica mais fácil (...)" (E 2).

“(...) mas nesse já tinha grupo de estudos, já tinha professor on-line não era tão computadorizado (...)" (E 6).

Outro aspecto destacado pelos sujeitos é que o material disponível oferecia grande auxilio durante a execução de um curso na modalidade a distância. A disponibilização destes materiais ampliava a possibilidade de pesquisa em várias fontes, a facilidade e agilidade no acesso as informações, além de facilitar o acesso à materiais bibliográficos.

“(...) Você não fica tão restrita. Igual aqui, se a gente pega um livro você fica restrita aquela página dele, na EaD não, você pesquisa várias fontes. Igual já aconteceu de eu pesquisar várias fontes pra montar um e isso abre o seu conhecimento, abre a sua cabeça, adquire mais conhecimento do assunto." (E'3).

"(...) A questão das apostilas que são disponibilizadas muito facilmente. Você pode ir lá 
pegar. Já tem uma referência pra você estudar, pra você se basear pra fazer aquela futura prova depois (...)" (E 5).

“(...) A facilidade de ter o livro disponivel que você não ter um computador ou tá conectado pra estudar. Eles também disponibilizaram o livro em PDF, então eu conseguia carregar ele no tablet onde você tivesse acesso, baixava e transportava (...)” (E 12).

A autonomia e a flexibilidade de horários proporcionada pela $\mathrm{EaD}$ também foi vista como um aspecto importante. Os entrevistados entenderam que o aluno é o centro do processo de ensino-aprendizagem, pois é ele quem determina o seu próprio ritmo de estudo e sua forma de fazê-lo. Também foi ressaltado o aprendizado colaborativo como uma experiência dos participantes na modalidade a distância.

“(...) A questão da autonomia que o aluno vai ter de fazer o seu tempo, isso eu vejo como um facilitador, porque ele vai fazer o horário dele. A questão da disciplina, que ele vai ter que trabalhar isso, acho que isso é um facilitador pra ele, porque ele não vai ter aquele horário rígido ali (...)" (E 7).

“(...) de todo jeito, lá a gente troca muito experiências, isso de toda forma a gente tá aprendendo e passando o conhecimento. Se lê uma coisa, você vai e coloca para todos, as vezes, outra pessoa não tem acesso aquele tipo de informação, ele adquire um conhecimento a partir do seu, então eu acho que é uma troca muito boa, tipo, entre várias pessoas de um grupo de ensino-aprendizagem, que consegue aprender através de colocações de outras pessoas..." (E 3 ).

Os sujeitos reconheceram que o estímulo ao estudo depende do próprio aluno e não o fato de ser presencial ou à distância. Reconheceram o estímulo como necessário para a dedicação aos estudos. Estes estímulos foram representados pela cobrança, avaliação, cumprimento de carga horária, nota, frequência, dentre outras.
“(...) Porque se for pra você comparar, dá aula aqui, da escola normal (presencial), com a aula lá, que é tudo via internet, eu acho que é a mesma coisa. Basta você querer e você tá incentivado né, a tá participando e fazendo todas as atividades lá dentro (...)” (E 1).

“(... “...nesse agora que eu tô fazendo a gente é avaliado, tem data pra entregar as coisas, tem a nota que sai e até o final do curso, você tem que atingir a carga horária. A cada monitoria, o tempo que você tá ali, né estudando e a frequência, a sua nota. E exige muita dedicação pra você poder estudar, você tem que estudar, né, preparar qualquer coisa que você vai escre$\operatorname{ver}(. .$.$) ) (Е 3).$

\section{Dificuldades vivenciadas pelos discentes de Enfermagem}

Primeiramente os entrevistados apontaram sentir a necessidade de comunicar com o professor, utilizando-se além da linguagem escrita. Alegaram não serem compreendidos, quando da escrita de seus questionamentos.

\begin{abstract}
“(...) Quando você usa um meio como a educação a distância, a gente percebe que essa própria distância ela cria um obstáculo, porque nem sempre você consegue pôr naquele portal, com as palavras que você gostaria de falar. Então isso acaba trazendo um equívoco na sua resposta, na sua pergunta (...)" (E 2).

“(...) eu acho meio difícil essa parte de você expressar por palavras escritas o que você quer dizer. As vezes você pode falar uma coisa que vai entender outra (...)" (E 3).
\end{abstract}

Os sujeitos destacaram a baixa interatividade em suas experiências. Também destacaram que as vídeo-aulas não suprem suas necessidades por respostas individualizadas.

\footnotetext{
“(...) O ambiente não tem uma interatividade tão grande, como, por exemplo, o facebook. Acho que falta isso, a interatividade ali (...)" (E 4).

“(...) No cursinho de inglês não, você escolhe e é
} 
uma máquina que fica a todo tempo te falando e fala pra mil alunos que tiver assistindo aquele horário (...)” (E 6).

“(...) Porque a gente tá acostumado com aquela linha, o professor numa sala cheia de alunose o professor ali o tempo inteiro. Você pode negociar com ele, você pode chegar, conversar, essas coisas. No ensino a distância você conversa mas não é tão próximo, você não tem essa proximidade assim com o professor (...)”(E 3).

Alguns dos participantes relataram dificuldades em relação à organização de seu tempo para dedicar-se a $\mathrm{EaD}$, em detrimento de outras atividades de seu cotidiano.

“(...) No início tava bem flexível, mas depois começou a bater muita coisa com a faculdade, no ensino a distância você tem a questão da escolha de horário, mas você não tem aquele tempo todo disponivel (...)" (E 6).

“(...) Encaixar o tempo em relação a faculdade pra poder, porque o curso a distância não é simplesmente pegar e sair pulando as páginas todas, pra ter um diploma, pra ter um certificado, você tem que ter tempo pra poder estudar mesmo (...)” (E 9).

Os participantes também alegaram dificuldades relacionadas com a tecnologia e com a baixa conectividade, representados por falhas no sistema e na comunicação por meio do acesso à internet.

“(...) Eu acho assim, que a dificuldade principal foi que, quando a gente precisava enviar algumas atividades não tinha como o sistema tava fora de área (...) E acabava que quando a gente enviava dava algum erro no sistema, falava que não enviou e foi enviado (...)" (E 1).

“(...) As dificuldades é que somos dependente da internet e essa internet, às vezes, falha ficamos a mercê disso. E às vezes, você manda o e-mail para o professor você tá achando que chegou e não chegou, fica aquela falha na comunicação (...)" (E 10).

\section{Processo de capacitação em EaD}

Quando questionados a respeito do processo de capacitação, apenas dois participantes relataram ter passado por capacitações relacionadas às ferramentas utilizadas na EaD. Além disso, deixaram dúvidas em seus discursos se estas capacitações foram suficientes.

\begin{abstract}
“(...) Sim. Um dia antes, eles marcaram tipo uma aula e ensinaram como seriam utilizadas as ferramentas pra aprender (...)" (E 1).

“(...) Então, a gente passou, não sei se foi algo bem completo. (...) eu tive recentemente uma capacitação referente ao Moodle, que é o portal que a gente usa pra educação a distância aqui na instituição. Eu acho que é interessante, agora, não sei se é o completo, creio que não, mas o basicão a gente teve (...)” (E 2).
\end{abstract}

Outros discentes de Enfermagem também destacaram que não passaram por um processo de capacitação e isto dificultou o desenvolvimento do curso. Alguns relataram que aprenderam a usar as ferramentas por meio da curiosidade, tentativas e até pela ajuda de outros.

“(...) Não passei por nenhum processo de capacitação (...) mas eu acho que faltou uma aula inicial, sabe, de apresentação inicial, de olha vai ser assim ou vai ser assim que tem que manipular o sistema, os temas vão ser debatidos são esses, esses e esses (...)” (E 4).

“(...) Não, nada. Simplesmente entrando e acessando. Mas descobri através de outras pessoas e foi, acessei, entrei e de acordo com os passos que lá estavam eu fui entrando e acessei. (...). Agora se tivesse tido capacitação com certeza seria importante (...)” (E 5).

\section{DISCUSSÃO E CONCLUSÃO}

As experiências vivenciadas pelos discentes de Enfermagem na modalidade a distância 
se desenvolveram de diferentes formas, sendo dentro da própria universidade e também em outros cenários de aprendizagem não vinculados ao curso de Enfermagem. Isto demonstra que a EAD tem proporcionado aos discentes de Enfermagem a diversidade de possibilidades e contextos de aprendizado. Ora se estabelecem dentro da universidade onde estão se formando ora compartilham outros conhecimentos em outras áreas. Isso reforça a idéia de que a Enfermagem têm utilizando cada vez mais, processos educacionais mediados por novas tecnologias de informação e comunicação, especialmente na $\mathrm{EaD}(16)$.

Neste sentido não há limites para vivenciarem e experimentarem de diversas fontes de informação e conhecimento. Este caráter flexível, atemporal e inovador enriquece a formação do enfermeiro para uma sociedade em rede e vinculada à era Digital. Além disso, amplia as suas possibilidades de formação e atuação reconhecendo outras fontes de saber em uma realidade de mercado cada vez mais competitiva. Não se trata de descaracterizar o objeto do cuidar como a base do conhecimento em enfermagem, mas enriquecê-lo para além dos muros de uma universidade, um campus, um professor, uma biblioteca e alguns livros. A rede de conhecimentos na $\mathrm{EaD}$ é tecida e sobrevive a partir de compartilhamentos e interações. É nesse universo que a Enfermagem tem sido envolvida e não deve alijar-se desse processo.

Várias facilidades do uso da $\mathrm{EaD}$ foram reconhecidas, destacando-se a flexibilidade de tempo e local para estudo, o baixo custo, a redução de deslocamento, a agilidade no acesso às várias fontes de informação e o aprendizado colaborativo. Estas facilidades também foram verificadas em outros estudos $(9,17)$. Além disso, a $\mathrm{EaD}$ potencializa estímulos e desafios para a prática da curiosidade, o que auxilia na construção da autonomia do aluno. Assim, os envolvidos com a $\mathrm{EaD}$ são estimulados a determinar sua melhor forma de aprendizado. Com os avanços das redes e da modalidade a distância as pessoas estão aprendendo de forma flexível, horizontal, informal, independente e de forma mais colaborativa (18). As facilidades proporcionadas na $\mathrm{EaD}$ são fundamentais para a Enfermagem, principalmente para um país continental como o Brasil e marcado pela exclusão social. A mobilidade e a autonomia conferida ao alunos de enfermagem são fundamentais para a formação de profissionais nos vários Estados brasileiros e com a característica marcante da autonomia, onde esses profissionais saibam lhe dar com os problemas e determinantes de saúde de maneira inovadora.

Apesar da ampliação das possibilidades de aprendizado e das facilidades que a $\mathrm{EaD}$ proporciona aos discentes de Enfermagem algumas dificuldades se destacaram. Estão relacionadas a aspectos tecnológicos (hardware, software e conectividade), dificuldades relacionadas a interação professor/aluno e a dificuldade de comunicação apenas pela escrita. Ressalta-se ainda como aspectos dificultadores a dependência do professor, a dificuldade de organizar o próprio tempo, o processo de capacitação assistemático, insuficiente e com repercussões sobre o desenvolvimento do curso na modalidade a distância.

As dificuldades verificadas neste estudo demonstram, primeiramente, que há aspectos relacionados à própria pessoa, em sua individualidade e subjetividade que podem influenciar no desenvolvimento do processo de aprendizado na modalidade à distância. Atualmente espera-se que o aluno busque construir seu conhecimento, seja flexível, saiba lidar com as necessidades de maneira criativa e que manifeste vontade de aprender (19). É importante destacar que na modalidade a distância, o aluno não deve ser considerado apenas um receptor de idéias, sendo necessário estimulá-lo a tornar-se um elemento interativo no processo educacional (20).

Porém há outras dificuldades, além da subjetividade do sujeito, concentram-se na própria concepção do curso, seu modelo pe- 
dagógico, sua formatação e os aspectos tecnológicos envolvidos. Algumas instituições promotoras de cursos na modalidade a distância, ainda mantêm uma concepção pedagógica predominantemente tradicional em que o professor-autor ainda é o responsável pelo conteúdo do curso e por torná-lo acessível. Já o papel dos alunos continua sendo secundário, o de ler (ou escutar), compreender e realizar as atividades propostas (18). Isto talvez justifique os relatos dos discentes neste estudo sobre a dificuldade em relação a presença física do professor. $\mathrm{Na} \mathrm{EaD}$ é necessário estabelecer e pactuar novas formas de interação com o aluno, que considere as diversas possibilidades de aprendizado, de maneira formal e informal, de maneira presencial ou virtual ou em qualquer outro lugar, em qualquer horário, podendo esse aprendizado ser de forma individual ou compartilhada (18).

Em relação a formatação de cursos na modalidade torna-se fundamental a preparação de profissionais de design, programação e desenvolvimento de ambientes computacionais que entendam as necessidades educacionais (19). No que tange aos aspectos tecnológicos envolvidos nas experiências em EAD, é necessário potencializar o uso de outras tecnologias além dos ambientes virtuais de aprendizado (18). É possível utilizar outros recursos como redes sociais, teleconferências, web conferências, dentre outras possibilidades. Esta diversidade de abordagem, na $\mathrm{EaD}$ potencializam o seu sucesso e devem ser ampliadas no contexto da enfermagem. Esta combinação de tecnologias pode suplantar dificuldades na modalidade como as percebidas neste estudo relacionado à baixa interatividade, a comunicação focada na escrita e a falta da personalização do processo.

Também verificou-se a necessidade de um processo de capacitação sistemático e contínuo no que tange às ferramentas da $\mathrm{EaD}$. Isto precisa ser institucionalizado e planejado quando da implantação de um curso com vistas à qualificar o processo de ensino-aprendizagem no contexto da enfermagem. Não basta esperar que o aluno, na EaD, de forma intuitiva, seja capaz de se articular e aprender "de repente" a partir de um envolvimento coletivo, com os demais participantes. O manuseio das ferramentas presentes em um curso na modalidade a distância também são passíveis de serem ensinados e entendidos.

Torna-se indispensável na prática da $\mathrm{EaD}$ a subcultura acadêmica que privilegia os conteúdos dos currículos e o seu rigor científico, a subcultura pedagógica/tecnológica que sublinha a qualidade da mediatização (estética e comunicacional) e a subcultura burocrática definindo prazos, custos e os critérios legais e financeiros. O sucesso de experiências na $\mathrm{EaD}$ no contexto da enfermagem também dependem do equilíbrio entre este tripé. Isto precisa fundamentar o planejamento destes cursos (21).

A análise das percepções dos discentes remetem a alguns desafios que necessitam de intervenções com vistas ao rearranjo da $\mathrm{EaD}$ no contexto da enfermagem. O primeiro desafio refere-se ao aparato tecnológico a ser manuseado durante o processo de ensino-aprendizado na modalidade a distância. É necessário adequação de layout ao entendimento dos participantes, a busca por uma conectividade consistente, a manutenção de um suporte técnico, bem como é preciso o avanço de tecnologias que promovam maior interatividade.

O segundo desafio é a necessidade do exercício da autonomia do aluno que precisa de fato ser capaz de se organizar para determinar o seu próprio ritmo de estudo-aprendizado. Isto não é uma tarefa fácil, pois perpassa por uma construção cultural e evolutiva, consequente de uma práxis educacional antes mesmo de sua chegada ao ensino superior. Para bons resultados de práticas educativas por meio da $\mathrm{EaD}$ é preciso alterar a lógica da transmissão de informações para a lógica da comunicação que envolve a interatividade e a criação de significado.

Na perspectiva da interatividade, o professor pode deixar de ser um transmissor de 
saberes para converter-se em formulador de problemas e provocador de interrogações. $\mathrm{O}$ ambiente colaborativo e interativo possui relevância no processo de ensino-aprendizagem. O desafio é a utilização da $\mathrm{EaD}$ como uma modalidade que ultrapasse o modelo de ensino tradicional focado no professor e na transmissão de informações. Não se pode utilizar da $\mathrm{EaD}$ para reforçar uma prática educacional centrada apenas na pergunta e resposta, repetindo o formato de uma sala de aula tradicional e sem sentido para os dias atuais. É preciso utilizar do caráter inovador, tecnológico e desafiador atribuído à EaD.

Outro desafio é a gestão de todo este processo que precisa ser institucionalizada, reconhecida e legitimada. O uso da EAD, no contexto da formação em enfermagem, não deve estar atrelado a um desejo pessoal de um professor em uma disciplina, mas é necessário a definição de uma política institucional de $\mathrm{EaD}$ que estabeleça de fato o seu papel na formação de profissionais de enfermagem.

\section{REFERÊNCIAS}

1. Decreto n. 5.622 de 19 de Dezembro de 2005 (BR). Regulamenta o art. 80 da Lei 9.394/96, de 20 de dezembro de 1996, que estabelece as diretrizes e bases da Educação Nacional. Publicado no Diário Oficial da União (Dez. 20, 2005).

2. Silva AN, Santos AMG, Cortez EA, Cordeiro BC. Limites e possibilidades do ensino à distância $(\mathrm{EaD})$ na educação permanente em saúde: revisão integrativa. Cien Saude Colet. 2015; 20(4): 10991107.

3. Souza DC, Diniz SOS, Silva PS, Silva TCT, Santiago LC. Educação à Distância: uma metodologia de ensino em expansão na enfermagem. Revista Rede de Cuidados em Saúde [Internet]. 2013 [citado 07 jan
2016]; 7(1). Disponível: http://publicacoes.unigranrio.br/index.php/rcs/article/ view/1859

4. Moore M, Kearsley G. Educação a Distância - Sistemas de Aprendizagem On-line. São Paulo: Cengage Learning; 2013. 430 p.

5. Moore MG. Handbook of Distance Education. 3th ed. New York: Routledge; 2013.897 p.

6. Holtslander LF, Racine L, Furniss S, Burles M, Turner H. Developing and piloting an online graduate nursing course focused on experiential learning of qualitative research methods. J Nurs Educ. 2012; 51(6): 345-8.

7. Ali WG. Factors affecting nursing student's satisfaction with e-learning experience in King Khalid University, Saudi Arabia. Int J Learn Develop [Internet]. 2012 [citado 07 jan 2016]; 2(2): 201-15. Disponível: http://dx.doi.org/10.5296/ ijld.v2i2.16662012; 2(2): 201-15.

8. Rangel-S ML, Barbosa AO, Riccio NCR, Souza JS. Redes de aprendizagem colaborativa: Contribuição da Educação a Distância no Processo de Qualificação de Gestores do Sistema Único de Saúde - SUS. Interface (Botucatu) [Internet]. 2012 Jun [citado 07 jan 2016]; 16(41): 545-55. Disponível: http://dx.doi. org/10.1590/S1414-32832012005000031.

9. Button D, Harrington A, Belan I. E-learning \& information communication technology (ICT) in nursing education: A review of the literature. Nurse Educ Today. 2014; 34(10): 1311-23.

10. Patterson BJ, Krouse AM, Roy L. Student outcomes of distance learning in nursing education: an integrative review. Comput Inform Nurs. 2012; 30(9): 475-88.

11. Pessoa SM, Sousa RA. Educação à distância e presencial: estratégias para os profissionais de enfermagem nos serviços de educação continuada. Texto contextoenferm. 2003; 12(2): 224-229. 
12. Minayo MC. Análise qualitativa: Teoria, Passos e fidedignidade. Cien Saude Colet. 2012; 17(3): 621-26.

13. Fontanella BJB, Luchesi BM, Saidel MGB, Ricas J, Turato ER, Melo DG. Amostragem em pesquisas qualitativas: proposta de procedimentos para constatar saturação teórica. Cad Saude Publica. 2011; 27(2): 388-394.

14. Fontanella BJB, Ricas J, Turato ER. Amostragem por saturação em pesquisas qualitativas em saúde: contribuições teóricas. Cad Saude Publica. 2008; 24(1): 17-27.

15. Bardin L. Análise de conteúdo. Lisboa: Edições 70; 2013. 223 p.

16. Camacho ACLF. Análise das publicações nacionais sobre educação à distância na enfermagem. Rev Bras Enferm. 2009; 62(4): 588-93.

17. Alves RHK, Cogo ALP. Vivência de estudantes de licenciatura em enfermagem em disciplina na modalidade a distância.
Rev Gaucha Enferm. 2008; 29(4): 626632.

18. Moran J. Educação a distância, mais focada em pesquisa e colaboração. En: Fidalgo FSR, org. Educação a distância: meios, atores e processos. 24 ed. Belo Horizonte: CAED - UFMG; 2013. p. 39-51.

19. Martins TYC, Ribeiro RC. Prado C. Transdiciplinaridade na educação à distância: um novo paradigma no ensino de Enfermagem. Rev Bras Enferm. 2011; 64(4): 779-82.

20. Prado C, Santiago LC, Silva JAM, Pereira IM, Leonello VM, Otrenti E, et al. Ambiente virtual de aprendizagem no ensino de enfermagem: relato de experiência. Rev Bras Enferm. 2012; 65(5): 862-6.

21. Carmo H. Tendências da Educação a Distância. En: Fidalgo FSR, org. Educação a distância: meios, atores e processos. 24 ed. Belo Horizonte: CAED - UFMG; 2013.p. 117-118. 